\title{
Differences in fatigue and psychological distress across occupations: results from the Maastricht Cohort study of fatigue at work
}

\author{
Citation for published version (APA): \\ Bültmann, U., Kant, Y., van Amelsvoort, L. G. P. M., van den Brandt, P. A., \& Kasl, S. V. (2001). \\ Differences in fatigue and psychological distress across occupations: results from the Maastricht Cohort \\ study of fatigue at work. Journal of Occupational and Environmental Medicine, 43, 976-983. \\ https://doi.org/10.1097/00043764-200111000-00008
}

\section{Document status and date: \\ Published: 01/01/2001}

DOI:

10.1097/00043764-200111000-00008

Document Version:

Publisher's PDF, also known as Version of record

Please check the document version of this publication:

- A submitted manuscript is the version of the article upon submission and before peer-review. There can be important differences between the submitted version and the official published version of record. People interested in the research are advised to contact the author for the final version of the publication, or visit the DOI to the publisher's website.

- The final author version and the galley proof are versions of the publication after peer review.

- The final published version features the final layout of the paper including the volume, issue and page numbers.

Link to publication

\footnotetext{
General rights rights.

- You may freely distribute the URL identifying the publication in the public portal. please follow below link for the End User Agreement:

www.umlib.nl/taverne-license

Take down policy

If you believe that this document breaches copyright please contact us at:

repository@maastrichtuniversity.nl

providing details and we will investigate your claim.
}

Copyright and moral rights for the publications made accessible in the public portal are retained by the authors and/or other copyright owners and it is a condition of accessing publications that users recognise and abide by the legal requirements associated with these

- Users may download and print one copy of any publication from the public portal for the purpose of private study or research.

- You may not further distribute the material or use it for any profit-making activity or commercial gain

If the publication is distributed under the terms of Article $25 \mathrm{fa}$ of the Dutch Copyright Act, indicated by the "Taverne" license above, 


\section{Differences in Fatigue and Psychological Distress Across Occupations: Results From The Maastricht Cohort Study of Fatigue at Work}

\author{
Ute Bültmann, MSc \\ IJmert Kant, PhD \\ Ludovic G. P. M. van Amelsvoort, PhD \\ Piet A. van den Brandt, PhD \\ Stanislav V. Kasl, PhD
}

Differences in fatigue and psychological distress across occupations were examined among 8521 employees participating in the Maastricht Cohort Study of "Fatigue at Work." Additional information on the perceived psychosocial work environment was incorporated. A total of 131 occupations, classified according to the Netherlands Standard Classification of Occupations 1992, were studied. Results showed that occupation as a proxy index of the "objective" work environment adds little explanatory information beyond perceived measures of the work environment. Although "occupation" seems to be an easy entree for intervention, focusing on occupation exclusively to prevent, or at least reduce, fatigue and psychological distress may be inadequate. Supplementary information about the perceived work environment of the job occupant is needed to develop preventive measures on the individual level. Further research, including a longitudinal analysis, is required to elucidate the complex relation between occupation, psychosocial risk factors, and fatigue and psychological distress. (J Occup Environ Med. 2001;43:976-983)

\footnotetext{
From the Department of Epidemiology, Maastricht University, Maastricht, The Netherlands (Ms Bültmann, Dr Kant, Dr van Amelsvoort, Dr van den Brandt); and the Department of Epidemiology and Public Health, Yale University School of Medicine (Dr Kasl).

Address correspondence to: Ute Bültmann, MSc, Department of Epidemiology, Maastricht University, PO Box 616, 6200 MD Maastricht, The Netherlands.

Copyright $($ ) by American College of Occupational and Environmental Medicine
}

I

t has long been recognized that fatigue is a common complaint among the general population and the working population. ${ }^{1-4}$ In recent years, interest in prolonged fatigue has grown in occupational (mental) health research ${ }^{5,6}$; prolonged fatigue may affect the individual's performance and ability to function in the occupational and home settings and may lead to absenteeism and work disability. ${ }^{7}$ Given the unfavorable prognosis of prolonged fatigue and the high social and economic costs, ${ }^{7}$ the development of preventive measures is of paramount importance. To gain insight into the prevalence and incidence of prolonged fatigue in the working population, and to examine the psychosocial risk factors in the etiology and natural course of prolonged fatigue, the large-scale epidemiological Maastricht Cohort Study of "Fatigue at Work" was established. ${ }^{8,9}$

Cross-sectional analyses with baseline data collected in this study showed that some degree of fatigue was present in nearly all of the working population, and that $22 \%$ of the 12,000 employees crossed the predefined cutoff point for fatigue and were designated as probable fatigue cases. The same study revealed that fatigue and psychological distress are fairly well associated in the working population $(r=0.62)$, and about $23 \%$ of study employees were considered to be probable cases of psychological distress. ${ }^{10}$ Moreover, 
in cross-sectional analyses, associations have been found between a wide range of psychosocial work characteristics and fatigue (manuscript submitted). Recently, longitudinal analyses of the Maastricht Cohort Study showed that psychosocial work characteristics are significant predictors for the onset of fatigue and psychological distress, after 1 year of follow-up in the working population and controlling for baseline values of the two outcome variables. For example, emotional, psychological, and physical demands at work are risk factors for future fatigue in men, whereas decision latitude and good interpersonal relationships at work protect against fatigue in both genders. These observed longitudinal associations suggest some differential effects of psychosocial work characteristics in the etiology of fatigue versus psychological distress. These work characteristics represent potentially modifiable factors that could be addressed to prevent, or at least reduce, the risk of fatigue and psychological distress in the working population (manuscript submitted).

So far, the analyses have ignored potential occupational differences in fatigue and psychological distress and have linked psychosocial work characteristics to fatigue and psychological distress across all occupations. This means that we do not know if some occupations are notably high or low on fatigue and psychological distress, and whether the perceptions of work characteristics in these occupations help to explain the differences in reported fatigue and psychological distress across occupations. In this article, we propose to use occupation as an additional measure of the work environment that is not dependent on the perceptions of the job occupants.

Strategies of exposure measurement in the field of work stress research have been subject of controversy for many years. ${ }^{1-16}$ Arguments have been made for both objective and subjective measures of the work environment, for new ap- proaches in the measurements, ${ }^{15}$ and for assessing the validity of such measurements. ${ }^{17}$ The issues remain largely unresolved, and the research community has not reached consensus, as can be seen in the recent exchange in the September 1999 issue of the Journal of Organizational Behavior. $^{18-20}$ Earlier, we argued ${ }^{13}$ (p 398) that "paying attention to job titles is a minimal strategy of using objective data and is often quite informative." Job titles or occupations can be viewed as a proxy index of the objective work environment, albeit a rather crude one; by using this additional information, we have a somewhat more complete picture of how the work environment influences fatigue and distress. Moreover, from the standpoint of developing preventive measures, occupations might help identify specific groups at risk and, in particular, might be the easiest entree for interventions.

The purpose of the present study is to address the following questions: (1) How much of the variance in fatigue and psychological distress is explained by occupation? (2) How much of the variance in psychosocial work characteristics is explained by occupation? (3) Will the explanatory power of occupation alone for fatigue and psychological distress be diminished if one psychosocial work characteristic, or all of them, are added to the model?

\section{Methods}

\section{The Maastricht Cohort Study}

In May 1998, the Maastricht Cohort Study of "Fatigue at Work" was started in the Netherlands. A total of 26,978 male and female employees, aged 18 to 65 , from 45 companies and organizations, received a letter at home inviting participation and the baseline questionnaire. This selfadministered questionnaire comprised items on psychosocial work characteristics, demographic, workfamily, health factors, fatigue, and psychological distress. Altogether 12,160 employees completed and re- turned the baseline questionnaire (response rate of $45 \%$ ). Sixty-six questionnaires were excluded from the analysis because the age criterion was not met or because of technical reasons. The study population at baseline consisted of 8840 men (73\%) and 3255 women $(27 \%)$. For the analyses reported below, the study population was restricted to those employees $(n=11,020)$ who did not report themselves as absent from work or working under modified conditions because of former sickness absence (eg, fewer hours, modified tasks, or other functions). Full details of the sampling, (non-) response, and baseline characteristics of the study population are reported elsewhere. ${ }^{10}$

\section{Assignment of Occupations}

Occupation was assessed by two open questions concerning the current job: "What is your job in the company/organization?" and "What is your most important task?" Trained coders used the responses to the open-ended questions to assign an occupation, expressed by a fivedigit code, based on The Netherlands Standard Classification of Occupations $1992 .{ }^{21}$ Examples include "assembler" (26511), "waiter/server" (37203), "head nurse" (69210), "designer/design engineer" (86602), and "manager public institution" (99101). Eighty-eight employees did not report their function or work activities, thus preventing the assignment of an occupation, and were excluded from the analysis. A total of 687 different occupations were assigned to the study population at baseline. The present analyses (1) are based on employees reporting to be at work at baseline $(n=11,020)$, and (2) use only occupations with at least 20 employees. This minimum number of employees within one occupation was chosen to provide an adequate basis for analysis. An "occupation" variable was created that included 131 different occupations, comprising a total of 8521 employees, thereby covering about 
$77 \%$ of the baseline population. Of these 131 occupations, only three were related exclusively to one company/organization, whereas the rest were distributed throughout different companies/organizations.

\section{Measurement of Fatigue}

Fatigue was measured with the self-report Checklist Individual Strength (CIS), which was originally developed for hospital studies of chronic fatigue syndrome. ${ }^{22,23}$ The 20 statements of the CIS cover several aspects of fatigue, such as severity, concentration, motivation, and physical activity level. The instrument was extensively tested in the clinical setting 24,25 and was validated in the working population. ${ }^{26}$ Employees were instructed to indicate how they had felt during the previous 2 weeks, and the response to each statement was scored on a seven-point Likert scale. Higher scores indicate a higher degree of fatigue, more concentration problems, reduced motivation, or low levels of activity. In the Maastricht Cohort Study, the CIS total score, ranging from 20 to 140 , was used to measure fatigue. A cutoff point for case classification of CIS total $>76$ was established in a separate pilot study by means of defined samples with differences in fatigue levels. ${ }^{8}$ All employees scoring $>76$ were designated as probable fatigue cases.

\section{Measurement of Psychological Distress}

Psychological distress was measured with the 12-item version of the General Health Questionnaire (GHQ-12). ${ }^{27,28}$ The GHQ-12 was developed as a screening instrument for minor psychiatric disorders in the general population. For the fourpoint response scale, two scoring systems were used. The Likert scoring method $(0,1,2,3)$ summed the responses of the 12 items to generate a continuous distribution, ranging from 0 to 36 . The traditional GHQ scoring method $(0,0,1,1)$ is designed to identify individuals report- ing sufficient psychological distress to be classified as probable cases of minor psychiatric disorder. Given a possible range of scores from 0 to 12 , the threshold for case classification in the present study was 4 or higher, meaning that employees scoring on 4 or more of the 12 items were considered to be probable cases of psychological distress. The threshold for case classification is high but comparable with that used in previous studies in the working population., ${ }^{3,29}$

\section{Measurement of Psychosocial Work Characteristics}

A validated Dutch version of the Job Content Questionnaire was used to assess psychological job demands, decision latitude, and social support at work. ${ }^{30,31}$ Psychological job demands were measured by the sum of five items (excessive work, conflicting demands, insufficient time to do work, work fast, and work hard). Decision latitude was assessed by the sum of two subscales: skill discretion (keep learning new things, can develop skills, job requires skills, task variety, work not repetitious, and job requires creativity) and decision authority (have freedom to make decisions, can choose how to perform work, and have a lot to say on the job). Social support was measured by two scales: (1) coworker support (they take a personal interest in me, are friendly, helpful in getting the job done, and competent in doing work); and (2) supervisor support (concerned about the welfare of those under him/her, pays attention, helpful in getting the job done, successful in getting people to work together). The response options for each item varied on a four-point scale, from "strongly agree" to "strongly disagree."

Emotional demands at work were measured by the sum of five items: confronted with personally upsetting things, personally attacked or threatened, gets annoyed with others, moving working situations, and one or more shocking events at work during the past year (eg, accident, violent crime, sexual harassment, aggression at work). The items were derived from a Dutch questionnaire on Work and Health, ${ }^{32}$ a Dutch questionnaire on Perception and Judgment of Work, ${ }^{33}$ and self-formulated (shocking events at work). To assess whether employees perceive their work as physically demanding, one item of the Dutch questionnaire on Work and Health ${ }^{32}$ was used. Three items from the Dutch questionnaire on Perception and Judgment of Work ${ }^{33}$ were used to measure conflicts with coworker, conflicts with supervisor, and job insecurity. The response option for each item was yes/no.

\section{Data Analytic Procedure}

All data were analyzed using SAS statistical software. ${ }^{34}$ To identify occupations high and low on fatigue and psychological distress, primarily descriptive analyses were performed. Prevalence was calculated for each occupation by applying the cutoff point of CIS total $>76$ for fatigue and the GHQ-12 threshold of 4 or more for psychological distress. Regarding psychosocial work characteristics, we calculated mean scores for each occupation. Analyses of variance (SAS General Linear Model procedure) were conducted to evaluate (1) how much of the variance in fatigue (continuous CIS score) and psychological distress (continuous GHQ score) among the 8521 employees was explained by occupation (between-occupation variance), and (2) how much of the variance in each psychosocial work characteristic was explained by occupation. Moreover, to investigate whether the explained variance due to occupation alone will be diminished if psychosocial work characteristics are added, analyses of variance (SAS General Linear Model procedure) were performed in two steps. First, each psychosocial work characteristic was added separately to occupation. Then, after computing the intercorrelations between the various psychosocial work characteris- 
tics to check for collinearity (no correlation exceeded 0.38), a multivariate analysis was conducted by entering all psychosocial work characteristics together. All analyses of variance were adjusted for age and gender. The results are presented as $R^{2}$ partial and $R^{2}$ total.

\section{Results}

\section{Prevalence of Fatigue and} Psychological Distress

The crude prevalence of fatigue and psychological distress varied considerably across the occupations. Table 1 presents a description of the 10 lowest and 10 highest prevalence of fatigue by occupation. A prevalence of zero was found in the occupation "economist/business economist" ( $n=36)$, and the occupation with the highest prevalence of fatigue $(43.5 \%)$ was "controller, tester electro-technical machinery" $(n=$ 23). As can be seen in Table 2, the occupation with the lowest prevalence of psychological distress $(4.3 \%)$ was "maternity care worker" $(n=23)$. The highest prevalence of psychological distress (45.5\%) was found among the occupation "controller, tester electro-technical machinery" $(n=22)$.

\section{Explained Variance in Fatigue, Psychological Distress, and Psychosocial Work Characteristics by Occupation}

Table 3 shows the explained variance in fatigue and psychological distress by occupation and the between-occupation variance for a wide range of psychosocial work characteristics. All analyses were adjusted for age and gender. Among the 8521 employees, occupation explained only $3.6 \%$ of the observed differences in fatigue, and even less of the variance in psychological distress $(2.6 \%)$. Regarding work characteristics, occupation explained most of the variance in physical demands $(37.5 \%)$, followed by decision latitude $(24.8 \%)$, and emotional demands (14.2\%). For example, mean scores for decision latitude (range, 24 to 96) varied between 52.3
(SD, 12.2) among "pollsters, code clerks and traffic tellers" $(n=20)$ and 82.8 (SD, 5.8) among "directors/

\section{TABLE 1}

Prevalence of Fatigue Across Selected Occupations $(n=8521)$

\begin{tabular}{lrc}
\multicolumn{1}{c}{ Occupation } & $\boldsymbol{n}$ & $\begin{array}{c}\text { Prevalence } \\
\text { (\%) }\end{array}$ \\
\hline Lowest prevalence & 36 & 0.0 \\
Economist, business economist & 44 & 4.5 \\
Plumber, heating engineer, gas fitter, pipefitter & 21 & 4.8 \\
Executive automation & 51 & 5.9 \\
Physical/speech/audio therapist & 34 & 6.1 \\
Telephone operator & 30 & 6.7 \\
Executive secretary & 31 & 9.4 \\
Accountant assistant, administrative assistant & 31 & 9.4 \\
Manager: building industry, security service, industrial & & \\
production, road construction, hydraulic engineering & 58 & 10.3 \\
Occupational/activity/play/music therapist & 111 & 11.7 \\
Home help, geriatric help, social work aide, nurse's aide & & \\
Highest prevalence & 23 & 43.5 \\
Controller, tester electro-technical machinery & 37 & 40.5 \\
Head waiter & 38 & 36.8 \\
Tax officer, customs officer & 30 & 36.7 \\
Car, carriage sprayer & 236 & 34.7 \\
Assembler: cars, office machines & 31 & 32.3 \\
Field worker: social services, sanitation, cleaning department & 96 & 32.2 \\
Statistical analyst, statistician & 22 & 31.8 \\
Loader, unloader, warehouse helper, mover & 26 & 30.8 \\
Supply clerk & 36 & 30.6 \\
Biological/zoological/botanical/physical/chemical analyst & & \\
\hline
\end{tabular}

\section{TABLE 2}

Prevalence of Psychological Distress Across Selected Occupations $(n=8521)$

\begin{tabular}{lrr}
\multicolumn{1}{c}{ Occupation } & $\boldsymbol{n}$ & $\begin{array}{c}\text { Prevalence } \\
\text { (\%) }\end{array}$ \\
\hline Lowest prevalence & 23 & 4.3 \\
Maternity care worker & 22 & 4.5 \\
Concrete worker, parquet (floor) layer, engineer & 27 & 7.4 \\
Accountant & 26 & 7.7 \\
District nurse, health care policy-making official & 57 & 8.8 \\
Production supervisor (automation) & 22 & 9.1 \\
Delivery man, truck driver & 43 & 9.3 \\
Plumber, heating engineer, gas fitter, pipefitter & 101 & 9.9 \\
Design engineer: energy and telecommunication, electronics, & & \\
$\quad$ electric motors & 40 & 10.0 \\
Food inspector & 46 & 10.9 \\
Foreman: glass, earthenware, paper, textile fabrics, food and & & \\
$\quad$ luxury food, petrochemical industry & & \\
Highest prevalence & 22 & 45.5 \\
Controller, tester electro-technical machinery & 20 & 40.0 \\
Archivist, librarian & 28 & 35.7 \\
Waiter, server & 42 & 33.3 \\
Typist, data typist & 33 & 33.3 \\
Manager: wholesale, retail trade, movie theater, & & \\
$\quad$ sales/purchasing department & 27 & 33.3 \\
Supply clerk & 31 & 32.3 \\
Social-cultural worker, social/welfare worker & 239 & 29.7 \\
Assembler: cars, office machines & 98 & 29.6 \\
Statistical analyst, statistician & 200 & 29.5 \\
Machinist: glass, earthenware, paper, textile fabrics, food and & & \\
$\quad$ luxury food, processing industry & & \\
\hline & & \\
\hline & & \\
\hline
\end{tabular}


TABLE 3

Explained Variance in Fatigue, Psychological Distress, and Psychosocial Work Characteristics by Occupation, Adjusted for Age and Gender

\begin{tabular}{lrrr} 
& $\begin{array}{c}\text { SS Regression } \\
\text { (Type III) }\end{array}$ & Corrected Total SS & $\boldsymbol{R}^{\mathbf{2}}$ \\
\hline Fatigue & 151365.88 & 4298903.47 & 0.036 \\
Psychological distress & 4934.57 & 200311.83 & 0.026 \\
Psychological demands & 15659.50 & 264538.42 & 0.061 \\
Decision latitude & 256321.73 & 1098929.68 & 0.248 \\
Coworker support & 820.09 & 21486.78 & 0.056 \\
Supervisor support & 2306.58 & 46064.83 & 0.058 \\
Emotional demands & 1746.29 & 13353.58 & 0.142 \\
Physical demands & 594.62 & 1646.39 & 0.375 \\
Conflict with coworker & 12.40 & 558.16 & 0.025 \\
Conflict with supervisor & 15.88 & 759.89 & 0.025 \\
Job insecurity & 24.95 & 595.44 & 0.046 \\
\hline
\end{tabular}

${ }^{*}$ SS, Sum of Squares.

managers governmental institution" $(n=21)$. With respect to emotional demands (range, 0 to 5), mean scores varied between 0.32 (SD, 0.67) among "system analysts, system designers, programmers" $(n=78)$ and 2.98 (SD, 1.3) among "firemen" $(n=32)$. Occupation explained only a little of the variance in conflicts with and support of supervisor/ coworker and in job insecurity. With respect to psychological job demands, $6.1 \%$ of the variance was explained by occupation.

\section{Explained Differences in Fatigue and Psychological Distress by Occupations Supplemented With Psychosocial Work Characteristics}

Table 4 presents the explained variance in fatigue by occupation, along with psychosocial work characteristics, entered separately and together. By adding decision latitude to occupation, the explained variance by occupation was reduced from $3.6 \%$ to $2.7 \%$, whereas decision latitude explained $5.3 \%$ of the observed differences in fatigue on the individual level. This implies that betweenoccupation differences in decision latitude explain part of the differences in fatigue on the individual level. Similarly, the addition of supervisor social support reduced the explained variance by occupation to
$2.7 \%$ and explained $4.6 \%$ of the variance in fatigue. In contrast, emotional demands explained $6 \%$ of the observed variance in fatigue on the individual level but did not reduce the explained variance by occupation. Thus, between-occupation differences in emotional demands do not explain differences in fatigue on the individual level, although emotional demands explained more of the variance in fatigue compared with the other work characteristics. When all psychosocial work characteristics were entered together, $6.3 \%$ of the observed differences in fatigue on the individual level were explained by these psychosocial work characteristics in addition to occupation $(3.5 \%)$. Table 4 also shows that the sum of the partial $\mathrm{R}^{2}$ values is $9.8 \%$, whereas the presented $\mathrm{R}^{2}$ total is $17.3 \%$. This means that $9.8 \%$ is the sum of the independent variances and another $7.5 \%$ is variance explained by shared pairs (or more) of variables and by age and gender.

The explained variances in psychological distress by occupation, along with separate psychosocial work characteristics and all work characteristics together, are shown in Table 5. Of the observed differences in psychological distress on the individual level, $2.6 \%$ were explained by occupation. This was slightly reduced to $2.2 \%$ when we controlled
TABLE 4

Explained Variance in Fatigue by Occupation and Psychosocial Work Characteristics $^{a}$

\begin{tabular}{lll} 
& \multicolumn{2}{c}{$R^{2}$} \\
\cline { 2 - 3 } & Partial & Total \\
\hline Occupation & $0.035^{\star \star}$ & \\
Psychological demands & $0.032^{\star \star}$ & 0.068 \\
Occupation & $0.027^{\star \star}$ & \\
Decision latitude & $0.053^{\star \star}$ & 0.089 \\
Occupation & $0.032^{\star \star}$ & \\
Coworker support & $0.019^{\star \star}$ & 0.055 \\
Occupation & $0.027^{\star \star}$ & \\
Supervisor support & $0.046^{\star \star}$ & 0.082 \\
Occupation & $0.038^{\star \star}$ & \\
Emotional demands & $0.060^{\star \star}$ & 0.096 \\
Occupation & $0.037^{\star \star}$ & \\
Physical demands & $0.027^{\star \star}$ & 0.063 \\
Occupation & $0.034^{\star \star}$ & \\
Conflict with coworker & $0.010^{\star \star}$ & 0.046 \\
Occupation & $0.031^{\star \star}$ & \\
Conflict with supervisor & $0.023^{\star \star}$ & 0.058 \\
Occupation & $0.034^{\star \star}$ & \\
Job insecurity & $0.016^{\star \star}$ & 0.053 \\
Occupation & $0.035^{\star \star}$ & \\
Psychological demands & $0.008^{\star \star}$ & \\
Decision latitude & $0.024^{\star \star}$ & \\
Coworker support & $0.001^{\star \star}$ & \\
Supervisor support & $0.003^{\star \star}$ & \\
Emotional demands & $0.017^{\star \star}$ & \\
Physical demands & $0.006^{\star *}$ & \\
Conflict with coworker & 0.0002 & \\
Conflict with supervisor & $0.0006^{\star}$ & \\
Job insecurity & $0.003^{\star *} 0.173$
\end{tabular}

a Univariate and multivariate analysis adjusted for age and gender.

${ }^{\star *} P<0.001$; * $P<0.05$.

for psychological job demands, which explained $4.5 \%$ of the observed differences in psychological distress on the individual level. The explained variance by occupation was reduced to $1.8 \%$ when supervisor social support, which explained $4.8 \%$ of the variance, was added. As in fatigue, emotional demands did not reduce the variance explained by occupation and accounted for $9.4 \%$ of the observed differences in psychological distress on the individual level. In the multivariate analyses, $7.1 \%$ of the observed differences in psychological distress on the individual level were explained by all psychosocial work characteristics to- 


\section{TABLE 5}

Explained Variance in Psychological

Distress by Occupation and

Psychosocial Work Characteristics ${ }^{a}$

\begin{tabular}{|c|c|c|}
\hline & \multicolumn{2}{|c|}{$R^{2}$} \\
\hline & Partial & Total \\
\hline Occupation & $0.022^{\star \star}$ & \\
\hline Psychological demands & $0.045^{\star *}$ & 0.070 \\
\hline Occupation & $0.021^{*}$ & \\
\hline Decision latitude & $0.034^{\star \star}$ & 0.060 \\
\hline Occupation & $0.023^{\star \star}$ & \\
\hline Coworker support & $0.019^{\star \star}$ & 0.045 \\
\hline Occupation & $0.018^{\dagger}$ & \\
\hline Supervisor support & $0.048^{\star \star}$ & 0.073 \\
\hline Occupation & $0.029^{\star \star}$ & \\
\hline Emotional demands & $0.094^{\star \star}$ & 0.119 \\
\hline Occupation & $0.028^{\star \star}$ & \\
\hline Physical demands & $0.022^{\star *}$ & 0.049 \\
\hline Occupation & $0.023^{\star *}$ & \\
\hline Conflict with coworker & $0.018^{\star \star}$ & 0.043 \\
\hline Occupation & $0.022^{\star *}$ & \\
\hline Conflict with supervisor & $0.036^{\star *}$ & 0.062 \\
\hline Occupation & $0.023^{\star \star}$ & \\
\hline Job insecurity & $0.026^{\star \star}$ & 0.052 \\
\hline Occupation & $0.027^{\star \star}$ & \\
\hline Psychological demands & $0.011^{\star \star}$ & \\
\hline Decision latitude & $0.012^{\star *}$ & \\
\hline Coworker support & $0.001^{*}$ & \\
\hline Supervisor support & $0.003^{\star \star}$ & \\
\hline Emotional demands & $0.030^{\star *}$ & \\
\hline Physical demands & $0.003^{\star \star}$ & \\
\hline Conflict with coworker & $0.0007^{\dagger}$ & \\
\hline Conflict with supervisor & $0.003^{\star *}$ & \\
\hline Job insecurity & $0.008^{\star \star}$ & 0.187 \\
\hline
\end{tabular}

${ }^{a}$ Univariate and multivariate analysis adjusted for age and gender.

${ }^{\star *} P<0.001 ;{ }^{*} P<0.01 ;{ }^{\dagger} P<0.05$.

gether, along with occupation $(2.7 \%)$.

\section{Discussion}

The present study found that occupation, as a proxy index of the objective work environment, explained only $3.6 \%$ and $2.6 \%$ of the observed differences in fatigue and psychological distress, respectively. Thus, occupation, which is measured separately from the perceptions of job occupants, adds relatively little explanatory information beyond perceived measures of the psychosocial work environment. Nevertheless, the analysis did identify occupations high and low on fatigue and psychological distress, and it showed some linkages of perceived psychosocial work conditions with objective occupations. In terms of developing measures to prevent, or at least reduce, fatigue and psychological distress, occupation alone seems to be an inappropriate entree for intervention. The study suggests that supplementary information about the perceived work environment is needed to provide a sound basis for the development of preventive measures on the individual level (ie, interventions tailored to the specific needs of employees).

To our knowledge, this is the first study to rank occupations according to fatigue and psychological distress. Fatigue, like many other conditions based on the presence of symptoms, is best viewed as a continuum ${ }^{35}$ rather than a dichotomy. The validated Checklist Individual Strength was used to measure fatigue in the working population. ${ }^{26}$ The Checklist cutoff point of $>76$ for fatigue was empirically derived in a separate pilot study. ${ }^{8}$ When using a cutoff point, however, one may lose important information. Therefore, fatigue (and psychological distress) should be treated as a continuous variable whenever possible.

We found considerable occupational differences regarding the prevalence of fatigue and psychological distress. Previous studies in occupational mental health research also described occupational differences with respect to such factors as prevalence of major depressive disorder ${ }^{36}$ or prevalence of depression and global health. ${ }^{37}$ Both were US studies; thus it is difficult to compare their results with the findings reported here, not only because of the occupational classification used (ie, Census code), but also because of the different outcome measures.

The high and low occupational groups for fatigue (Table 1) and psychological distress (Table 2) did not have the same occupations in them (with one exception), supporting the notion of different underlying concepts of fatigue and psychological distress. It is interesting to note that the occupation "controller/tester" scored high on both outcomes; that work environment might be conductive to both fatigue and psychological distress. Although the prevalence of fatigue and psychological distress may quite informative by helping to identifying high-level and low-level occupations, it should be remembered that the two factors may reflect other (sociodemographic) characteristics of the occupations besides the influence of the occupational environments on the workers.

Regarding the between-occupation variance explained by psychosocial work characteristics, as might be expected, the proportion was high for physical demands $(37.5 \%)$ and decision latitude $(24.8 \%)$. Both conditions are more anchored in the objective occupation, in contrast to such other work characteristics as conflict with coworker and supervisor, in which the proportion of explained variance by occupation is rather low. However, these conditions reflect interpersonal relations on the job and are not inherent to particular occupations. The results from this study are mainly consistent with the explained variances described in US random samples, ${ }^{38,39}$ though a direct comparison of between-occupation variances for these scales is hindered because of the different occupational classifications being used. For job insecurity, the between-occupation variances have been reported at around $10 \%,{ }^{38,39}$ whereas we found a between-occupation variance of $4.6 \%$. Whether national variations may partly account for the difference in explained variance or the distinct measurement of job insecurity cannot be determined. Concerning the poorly explained variance in psychological job demands, as we noted earlier (p 398), ${ }^{13}$ it is unclear whether the classification of occupations was too crude to recognize variation in job demands or whether job demands are a subjective reac- 
tion that cannot be correlated to objective work conditions. In addition, our question remains as to whether job demands measure psychological reactions to objective work conditions, albeit with enormous individual differences, or whether they measure mostly preexisting personal characteristics that would manifest themselves in a similar way on different jobs (p 398). ${ }^{13}$ Overall, the results from this study indicate that occupation is variably linked to psychosocial work characteristics, some of which correspond very poorly to the objective work environment (as effected by the occupation).

Several other issues regarding the use of occupation as a proxy index for the objective work environment must be acknowledged. First, occupation seems to be a rather crude, inexact objective measure. For example, it is possible that two employees with the same occupation who were asked to complete the questionnaire may actually work under different psychosocial work conditions in different companies or even within the same company or organization. In short, using occupation in analysis cannot even approximately substitute for the use of objectively measured individual dimensions of work (however difficult and laborious that may be), and it cannot be sensitive to variations in these objective dimensions within an occupation for subgroups of workers. However, when occupation is analyzed together with psychosocial work characteristics, as described in Table 4 and 5, it still explains part of the differences in either fatigue or psychological distress. Perhaps other variables linked to fatigue and psychological distress, such as preexisting personal characteristics or socioeconomic status (eg, income), are reflected by occupation. In the present study, personal characteristics and income were not assessed. Another issue concerns possible selfselection into some occupations. It cannot be disregarded that an individual at high risk for fatigue or psychological distress might have characteristics that select him or her into a particular occupation.

Given the cross-sectional nature of the present study, it is important to note that a secure interpretation concerning cause and effect is not possible. Nevertheless, the strength of this study is its use of occupation as a proxy index of the objective work environment, supplemented with perceived measures of the work environment, to explain differences in fatigue and psychological distress in a large working sample.

The psychosocial work characteristics listed together with occupation in Tables 4 and 5 explain $9.8 \%$ of the variance in both fatigue and psychological distress, and the total variance jointly explained is $17.3 \%$ and $18.7 \%$, respectively. These differences in explained total variance may be attributed to contributions of age and gender, along with occupation plus shared variance of pairs (or more) of variables. Whether more of the variance in fatigue and psychological distress can be explained when other work-related factors, domestic factors, or individual characteristics are added, and how the role of measurement error in fatigue and psychological distress affects the results, requires further examination, including research of a longitudinal nature.

In conclusion, although occupation seems to be an easy entree for intervention, attempts to prevent, or at least reduce, fatigue and psychological distress by focusing on occupation exclusively may be inadequate. The present study showed that it is probably more appropriate to use additional measures of the work environment as perceived by the job occupant to develop effective workplace interventions that focus on the individual rather than on the occupation alone. Further research is needed to clarify the role of preexisting personal characteristics regarding occupational differences in fatigue and psychological distress. With insight into the complex interplay of the factors involved in fatigue and psychological distress, adequate preventive measures can be developed.

\section{Acknowledgments}

The Maastricht Cohort Study is part of the Netherlands concerted research action on "Fatigue at Work" granted by the Netherlands Organization for Scientific Research. The present study was and is currently supported by a grant from the Netherlands Organization for Scientific Research (NWO grant no. 580-02.251).

\section{References}

1. Chen MK. The epidemiology of selfperceived fatigue among adults. Prev Med. 1986;15:74-81.

2. Pawlikowska T, Chalder T, Hirsch SR, Wallace P, Wright DJ, Wessely SC. Population based study of fatigue and psychological distress. BMJ. 1994;308:763766.

3. Hardy GE, Shapiro DA, Borrill CS. Fatigue in the workforce of National Health Service Trusts: levels of symptomatology and links with minor psychiatric disorder, demographic, occupational and work role factors. J Psychosom Res. 1997;43:8392.

4. Loge JH, Ekeberg O, Kaasa S. Fatigue in the general Norwegian population: normative data and associations. $J$ Psychosom Res. 1998;45:53-65.

5. Meijman T, Schaufeli W. Psychische vermoeidheid en arbeid. Ontwikkelingen in de A\&O-psychologie [Fatigue at work. Developments in I/O psychology]. De Psycholoog. 1996; June:236-241.

6. Mounstephen A, Sharpe M. Chronic fatigue syndrome and occupational health. Occup Med Oxf. 1997;47:217-27.

7. Schröer CAP. De toename van arbeidsongeschiktheid wegens psychische aandoeningen [The increase of work disability due to mental disorders]. Tijdschrift voor Bedrijfs- en Verzekeringsgeneeskunde. 1997;5:16-23.

8. Bültmann U, De Vries M, Beurskens AJHM, Bleijenberg G, Vercoulen JHMM, Kant IJ. Measurement of prolonged fatigue in the working population: determination of a cutoff point for the Checklist Individual Strength. J Occup Health Psychol. 2000;5:411-416.

9. Kant IJ, Beurskens A, Schröer C, Nijhuis F, van Schayck C, Swaen G. De Maastrichtse Cohort Studie naar langdurige psychische vermoeidheid in de arbeidssituatie [The Maastricht Cohort Study of prolonged fatigue at work]. $T B V .2000 ; 8$ : 226-232.

10. Bültmann U, Kant IJ, Kasl S, Beurskens A, Van den Brandt P. Fatigue and psychological distress in the working population: psychometrics, prevalence, and correlates. J Psychosom Res. In press. 
11. Kasl SV. Epidemiological contributions to the study of work stress. In: Cooper CL, Payne R, eds. Stress at Work. Chichester: Wiley; 1978:3-48.

12. Kasl SV. Methodologies in stress, and health: past difficulties, present dilemmas, future directions. In: Cooper CL, Kasl SV, eds. Stress and Health: Issues in Research Methodology. Chichester: Wiley; 1987:307-318.

13. Kasl SV. Measuring job stressors and studying the health impact of the work environment: an epidemiologic commentary. J Occup Health Psychol. 1998;3: 390-401.

14. Frese M, Zapf D. Methodological issues in the study of work stress: objective vs subjective measurement of work stress and the question of longitudinal studies. In: Cooper CL, Payne R, eds. Causes, Coping and Consequences of Stress at Work. Chichester: Wiley; 1988:375-411.

15. Kristensen TS. The demand-controlsupport model: methodological challenges for future research. Stress Med. 1995;11:17-26.

16. Kristensen TS. Job stress and cardiovascular disease: a theoretic critical review. J Occup Health Psychol. 1996;1:246260.

17. Semmer N, Zapf D, Greif S. 'Shared job strain.' A new approach for assessing the validity of job stress measurements. J Occup Organ Psychol. 1996;69:293310.

18. Frese M, Zapf D. On the importance of the objective environment in stress and attribution theory. Counterpoint to Perrewe and Zellars. J Organ Behav. 1999; 20:761-765.

19. Perrewe PL, Zellars KL. An examination of attributions and emotions in the transactional approach to the organizational stress process. J Organ Behav. 1999;20: 739-752.

20. Schaubroeck J. Should the subjective be the objective? On studying mental processes, coping behavior, and actual expo- sures in organizational stress research. J Organ Behav. 1999;20:753-760.

21. Central Bureau of Statistics. Standaard Beroepenclassificatie: 1992 [The Netherlands Standard Classification of Occupations: 1992]. 's-Gravenhage: SDU/ uitgeverij; 1993.

22. Vercoulen JH, Swanink CM, Fennis JF, Galama JM, van der Meer JW, Bleijenberg G. Dimensional assessment of chronic fatigue syndrome. $J$ Psychosom Res. 1994;38:383-392.

23. Vercoulen JHHM, Alberts M, Bleijenberg G. De Checklist Individuele Spankracht (CIS) [The Checklist Individual Strength (CIS)]. Gedragstherapie. 1999; 32:131-136.

24. Vercoulen JH, Hommes OR, Swanink $\mathrm{CM}$, et al. The measurement of fatigue in patients with multiple sclerosis. A multidimensional comparison with patients with chronic fatigue syndrome and healthy subjects. Arch Neurol. 1996;53: 642-649.

25. Vercoulen JH, Swanink CM, Fennis JF, Galama JM, van der Meer JW, Bleijenberg G. Prognosis in chronic fatigue syndrome: a prospective study on the natural course. J Neurol Neurosurg Psychiatry. 1996;60:489-494.

26. Beurskens AJ, Bültmann U, Kant IJ, Vercoulen JH, Bleijenberg G, Swaen GM. Fatigue among working people: validity of a questionnaire measure. Occup Environ Med. 2000;57:353-357.

27. Goldberg DP, Williams P. A User's Guide to the General Health Questionnaire. Windsor: NFER-Nelson; 1988.

28. Koeter MWJ, Ormel J. General Health Questionnaire, Handleiding Nederlandse bewerking [General Health Questionnaire, Manual Dutch version]. Lisse: Swets \& Zeitlinger; 1991.

29. Wall TD, Bolden RI, Borrill CS, et al. Minor psychiatric disorder in NHS trust staff: occupational and gender differences. Br J Psychiatry. 1997;171:519-523.
30. Karasek RA. Job Content Questionnaire and Users's Guide. Los Angeles: University of Southern California, Department of Industrial and Systems Engineering; 1985.

31. Houtman I. Reliability and Validity of the Dutch Version of the Karasek Job Content Questionnaire: Proceedings of the NIOSH/APA Conference on Stress, Work, and Health, Washington, DC, 1995.

32. Gründemann R, Smulders P, de Winter C. Handleiding Vragenlijst Arbeid en Gezondheid [Questionnaire on Work and Health. Manual]. Lisse: Swets \& Zeitlinger; 1993.

33. Van Veldhoven M, Meijman T. Het meten van psychosociale arbeidsbelasting met een vragenlijst: De Vragenlijst Beleving en Beoordeling van de Arbeid (VBBA) [Questionnaire on Perception and Judgment of Work]. Amsterdam: NIA; 1994

34. SAS Institute. SAS version 6.12. Cary, NC; 1989.

35. Lewis G, Wessely S. The epidemiology of fatigue: more questions than answers. J Epidemiol Community Health. 1992;46: 92-97.

36. Eaton WW, Anthony JC, Mandel W, Garrison R. Occupations and the prevalence of major depressive disorder. J Occup Med. 1990;32:1079-1087.

37. Grosch JW, Murphy LR. Occupational differences in depression and global health: results from a national sample of US workers. J Occup Environ Med. 1998;40:153-164.

38. Karasek R, Theorell T. Healthy Work: Stress, Productivity, and the Reconstruction of Working Life. New York: Basic Books; 1990

39. Karasek R, Brisson C, Kawakami N, Houtman I, Bongers P, Amick B. The Job Content Questionnaire (JCQ): an instrument for internationally comparative assessments of psychosocial job characteristics. J Occup Health Psychol. 1998;3: 322-355. 